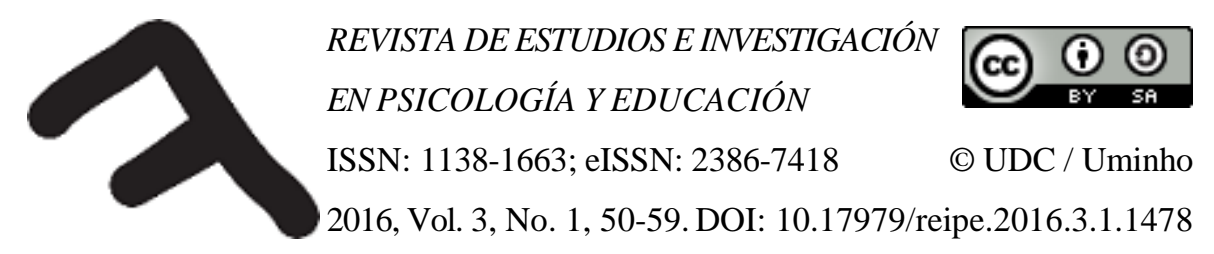

\title{
Lego Robots \& Autism Spectrum Disorder: a potential partnership?
}

\author{
Robô Lego \& Perturbações do Espetro do Autismo: Uma potencial parceria? \\ Sandra Costa*, Filomena Soares*, Cristina Santos*, Ana P. Pereira*, M. Fátima Moreira** \\ *Universidade do Minho, **APPACDM Braga
}

\begin{abstract}
Individuals with autism spectrum disorder (ASD) present difficulties in developing social behaviours, in communicating gestural or verbally, and they may present some repetitive motor activities. The objective of this study was to improve social competences and to enable the transfer of acquired skills of five children with ASD and intellectual disabilities using a low-cost Lego robot as a mediator. The proposed methodology was divided in five phases: Familiarization, Pre-test, Practice, Post-Test and Transfer of Skills. The study ran in two sequential periods at different places. Each of these periods tackled different individual research questions and goals (taking into account the target group). During each period, the proposed methodology had to be adjusted according to the current context. Therefore, different experimental scenarios and corresponding specific goals had to be delineated. Results show that joint attention of the children increased over the sessions; and interaction with the researcher was verified. Furthermore, results show that there was an effective transfer of skills in the addressed case studies. This reinforces conclusions that robots seem, in fact, powerful tools that should be explored concerning this target population. But a more detailed study is required. The proposed methodology can be used by professionals and parents as a complement to common interventions.
\end{abstract}

Keywords: autism spectrum disorder, assistive robotics, social interaction, human-robot interaction

\section{Resumo}

A perturbação do espectro do autismo (PEA) caracteriza-se por dificuldades no desenvolvimento de comportamentos sociais, na comunicação verbal ou gestual, e pela manifestação de atividades motoras repetitivas. O objetivo deste estudo foi o de melhorar as competências sociais e a transferência das competências de cinco crianças com PEA e deficiência mental associada usando um robô de baixo custo da Lego como um mediador. A metodologia proposta foi dividida em cinco fases: familiarização, pré-teste, prática, pós-teste e transferência de competências. O estudo foi realizado em dois períodos sequenciais em diferentes lugares. Em cada período foram definidas diferentes questões de investigação tendo em conta o grupo-alvo. Os resultados mostram que a atenção conjunta e a interação com o investigador aumentaram ao longo das sessões. Além disso, os resultados indicam que houve uma transferência efetiva de competências nos estudos de caso abordados. Isso reforça as conclusões que o robô da Lego pode ser uma ferramenta adequada a ser explorada com esta população-alvo. No entanto, é necessário um estudo mais detalhado e com uma amostra maior. A metodologia proposta pode ser usada por profissionais e pais como complemento às intervenções tradicionais.

Palavras chave: perturbação do espectro do autismo, robótica de assistência, interação social, interação humano-robô

Sandra Costa, Filomena Soares: R\&D Centre Algoritmi, Universidade do Minho, Campus de Azurém, 4800-058 Guimarães, Portugal. Ana P. Pereira: Education Research Center, Institute of Education, University of Minho, Campus de Gualtar 4710-057 Braga, Portugal. M. Fátima Moreira: APPACDM, Rua de S. Lázaro 38 S, José de S. Lázaro 4700-321 Braga, Portugal.

Correspondence concerning this article should be addressed to: Filomena O. Soares - fsoares@ dei.uminho.pt 
Autism Spectrum Disorder (ASD) is mainly characterized by two main alterations in behaviour: qualitative changes in social communication, with the pursuit of isolation, instrumental relationships, absence of awareness of emotions and feelings, and difficulty in imitating actions or situations; and a reduced and repetitive repertoire of activities and interests (APA, 2013). This leads to the need for immutability in daily routines, the absorbing interest for one or more repetitive patterns that are restrictive of their interest (Conroy, Boyd, Asmus, \& Madera, 2007; Rutherford \& McIntosh, 2007).

It is well-known that early intervention may improve results (Olley, 2005). Applied behaviour analysis (ABA), the TEACCH method, developmental models, speech and language therapy, social skills instruction, occupational therapy, and sensory integration therapy are some of the intervention strategies to enhance communication (Marans, Rubin, \& Laurent, 2005; National Research Council, 2001; Paul \& Sutherland, 2005), to teach social skills (Bregman, Zager, \& Gerdtz, 2005; Paul \& Sutherland, 2005; Taylor, 2001) and to reduce some typical behaviours (Bregman et al., 2005; Campbell, 2003; Horner, Carr, Strain, Todd, \& Reed, 2002). The research focuses on the use of robots in the classroom with the main goal of promoting the development of the children's cognitive capabilities, social interaction and communication skills, supporting the work of professionals, therapists and families (Billard, Robins, Dautenhahn, Nadel, 2007; Billard, Duquette, Michaud, \& Mercier, 2008; Brooks, Breazeal, Marjanovic, Scassellati, \& Williamson, 1998; Davis, Otero, Dautenhahn, Nehaniv, \& Powell, 2007; Dautenhahn, 1999; Ferrari, Robins, \& Dautenhahn, 2009; Giullian, Ricks, Atherton, Colton, Goodrich, \& Brinton, 2010; Ito \& Tani, 2004; Kozima, Nakagawa, \& Yasuda, 2007; Kozima, Michalowski, \& Nakagawa, 2008; Robins, Ferrari, \& Dautenhahn, 2007; Robins, Dautenhahn, \& Dickerson, 2009). Robots seem to work as a key tool able to draw the attention of children with ASD, and therefore promote their cognitive and social development (Salter, Werry, \& Michaud, 2008).

In fact, in recent years, several projects have been using robots in ASD intervention, as these tools may improve lacking skills in children with ASD such as joint attention, imitation, communication and social interaction (Billard, Robins, Dautenhahn, Nadel, 2007; Davis et al., 2007; Dautenhahn, 1999; Brooks, Breazeal, Marjanovic, Scassellati, \& Williamson,1998; Duquette et al., 2008; Ferrari et al., 2009; Giullian et al. 2010; Ito \& Tani, 2004; Kozima, et al., 2007 Kozima, et al., 2007; Kozima et al., 2008; Noris et al., 2007; Robins et al., 2007; Robins et al., 2009; Salter et al., 2008; Warren et.al., 2013).

These children are highly engaged by robots and they often interact better with the robot than with other human beings. In addition to this, robots have been used to facilitate the therapeutic process of children with ASD, with the robot acting as a mediator between the child and the therapist, or other person.
Due to the complexity of the problem and to the lack of generalization among the ASD population, these are still questions too difficult to assess. Thus, in this paper we explore the potential of LEGO robot in social interactions using a case-study design, focusing on the concept of skills generalization when modifying the environment, task execution location, and by changing the scenario when playing/interacting with an unknown partner. Also, a casestudy follow-up is presented in order to understand if the robot used in a triadic relationship can help in reducing repetitive motor manifestations.

The work presented in this paper is part of the research project Robótica-Autismo (www.robotica-autismo.com). This study used a Lego robot in triadic relationships with children with ASD and it took place in two educational institutions in Braga, Portugal: APPDA-Norte (two children) and Special Education's Unit of Gualtar Primary School (one child).

In order to establish the activities to be performed, caregivers, therapists, and researchers discussed and planned in detail the experiment, according to each child's characteristics.

Prior to the experiments, the Rector of University of Minho, the director of APPDA-Norte and the director of the primary school of Gualtar, Braga signed a research collaboration protocol where the investigation procedures were defined in common agreement. APPDA-Norte and the primary school informed the legal responsible of the children of the nature of the research experiences and obtained the informed consent.

\section{Method}

\section{Participants}

The addressed target group was composed by two children with ASD with 7 years old, Case 3 and Case 4. Case 3 is a boy who uses verbal communication but has difficulty to concentrate in one specific task. The goal was to work communication and interaction skills, and also to encourage him to ask for the robot's action, promoting joint attention. Case 4 is a boy who has no verbal communication and he performs repetitive motor movements consistently, having low control of his movements. In this way, the goal for Case 4 was to work social interaction and reducing repetitive motor movements over the sessions.

\section{Instrument}

The robot used in the experiments was a $L E G O$ Mindstorms NTX (www.lego.com). LEGO Mindstorms NTX is a programmable robotic kit released by Lego. This robot is low cost, modular, has a user-friendly interface, and also the robot configuration can gradually evolve. In this work, two different configurations (a non-human-like and a human-like shape) were considered, Figure 1 a) and b), respectively.

The robot is equipped with touch, light, and sound 
sensors. The experiments were designed to attract the children's attention and also to elicit their sensory motor coordination, while promoting their skills. Therefore, touch and sound were the selected sensory events to attract the children's attention and drive their action, allowing to program scripted choreographies.
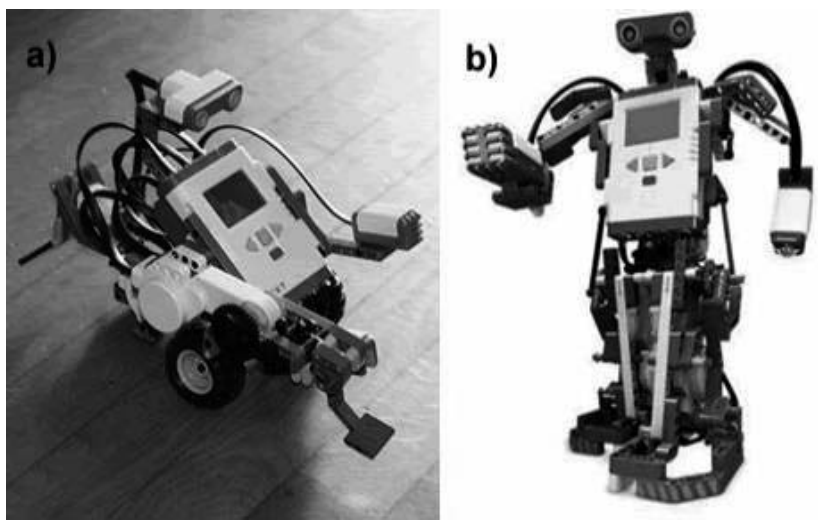

Figure 1 a) Robot configuration; $b$ ) Robot configuration 2

\section{Procedure}

In order to analyze children's behaviour along the experiments, all the sessions were recorded on video and the results were quantified in term of pre-defined indicators which measured several actions executed by the child, namely:

1. Reaction to the robot: Ignores the robot (Ignores); Displays repetitive motor movements (Manifests); Fixes in some detail (Fixes).

2. Action (behaviours started by free will): Intentionality to manipulate an object (Manipulates); Answers to request (Orders) - Transfer of Skills Phase; Expresses any kind of verbalization (Verbalizes) - Reaction Phase; Sends the ball back to the robot (Throws Ball) Reaction Phase.

3. Investment in the subject: Interaction time around holding/handling the robot.

The proposed methodology is divided in five phases: Familiarization, Pre-test, Practice, Post-Test, and Transfer of Skills.

The main goal of the first phase, Familiarization, was to get acquainted with the child and to integrate the researcher in his/her school environment.

The Pre-test phase was the first test with the child, robot, and researcher in the classroom. The goal was to check the first reactions carried out by the child towards the robot; this test was considered the reference to be compared to later test stages, where some variables were then changed.

The third phase, Practice, ran in the classroom with the child, robot, and researcher over three days a week, during ten minutes sessions. In this phase, the task was introduced in the child daily work.

The Post-Test phase was performed on a different day. This phase had the goal to evaluate the child's learning consistency. This way, after the interruption of the sessions, we would be able to see if the child was capable of performing that task.

Finally, the Transfer of Skills phase was performed during two weeks in two sessions. The main goal of this phase was to perform changes of context/models of the experiment, to evaluate the child performance and compare to the Pre-Test results. Different environments and models were tested allowing to verify if the robot worked as a promoter of social interactions.

The study ran in two sequential periods at different places. During each period, the proposed methodology had to be adjusted according to the current context. Therefore, different experimental scenarios and corresponding specific goals were specified.

Table 1 presents each period in terms of place, target group and experimental scenarios.

Table 1.

Periods of the Study

\begin{tabular}{|c|c|c|c|}
\hline Period & Place & Target Group & $\begin{array}{c}\text { Experiments and } \\
\text { Tasks }\end{array}$ \\
\hline Period 1 & $\begin{array}{l}\text { APPDA- } \\
\text { Norte }\end{array}$ & $\begin{array}{c}2 \text { children with } 7 \\
\text { years old: Case } 3 \\
\text { and Case } 4\end{array}$ & $\begin{array}{c}\text { Task } 1 \text { (Sound } \\
\text { game), Task } 2 \text { (Ball } \\
\text { game), Task } 3 \text { (Call } \\
\text { the robot game) }\end{array}$ \\
\hline Period 2 & Gualtar & $\begin{array}{c}1 \text { child with } 11 \\
\text { years old: Case } 5\end{array}$ & $\begin{array}{c}\text { Task } 1 \text { (Throw the } \\
\text { ball game) }\end{array}$ \\
\hline
\end{tabular}

\section{Period 1.}

The goal of Period 1 was to understand if the robot may could influence the children's motor manifestations and improve joint attention. The research question was: 'Can the robot be used to reduce repetitive motor movements and improve joint attention in children with ASD?' The different experiments in this phase took place in the facilities of the APPDA-Norte in Braga.

Each session comprised three tasks, as follows:

Task 1 - Activation of the robot through sound. The robot executed a predefined choreography while music from a computer was playing. Alternatively, the sound to activate the movement could be from hands clapping. This task was always performed on the floor.

Task 2 - Ball Game. In this task, there was a rail between the child and the robot. Once the child threw the ball towards the robot through the rail, the robot kicked the ball back to him.

Task 3 - Call the Robot. On the floor, with the child at one end of the room and the robot at the other end, the child called the robot to come in his direction (movement done in a straight line).

The configuration of the robot in these tasks was the same of Figure 1 a). Each session lasted between 20 to 30 
minutes, depending on the will of the child and they were weekly for 3 weeks. In summary, Period 1 followed the methodology previously defined up to the Practice phase. Table 2 summarizes the phases.

Table 2.

Phases of Period 1

\begin{tabular}{lcccc}
\hline & & \multicolumn{3}{c}{ Sessions } \\
Phase & Participants & $N$ & $D(\min )$ & $F$ \\
\hline Familiarization & $\mathrm{R} \& \mathrm{C}$ & 1 & 20 & 1 day \\
Pre-Test & $\mathrm{R}, \mathrm{C} \& \mathrm{R}$ & 1 & 20 & 1 day \\
Practice & $\mathrm{R}, \mathrm{C} \& \mathrm{R}$ & 2 & 20 & 1 day \\
\hline
\end{tabular}

Note: $\mathrm{R}=$ researcher, $\mathrm{C}=$ child, $\mathrm{R}=$ robot, $\mathrm{N}=$ number, $\mathrm{D}$ $=$ duration, $\mathrm{F}=$ frequency

Period 2.

In Period 2, the research question to be solved was: 'Can the robot be used as a stimulus in establishing social interactions with children with ASD, in new context and environments? The goal in this period was to verify if the competence previously developed with the robot as a mediator was transferred to new contexts.

The sessions took place at the Primary School of Gualtar in Braga, in the Special Education Unit Department. An 11 years old child with ASD, Case 5, participated in the experiments. He is not able to speak, but he is capable of producing vocalizations. He manifests difficulties in establishing eye contact while interacting with pairs and adults and, above all, he presents difficulties in directing and maintaining attention. He reacts strongly to changes in his daily routine by crying or even by being aggressive.

The activity set-up was constituted by: the researcher and the child, the robot, a rail and a ball. In the task, the child launched a ball in the direction of the robot, upon request from the adult, and the robot sent the ball back to the child, only upon child's verbal request. Table 3 details the phases of the proposed methodology. Table 4 summarizes the tested configurations in the Transfer of Skills.

Table 3.

Phases of Period 2

\begin{tabular}{lcccc}
\hline & & \multicolumn{2}{c}{ Sessions } \\
Phase & Participants & $N$ & $D$ (min) & $F$ \\
\hline Familiarization & $\mathrm{R} \& \mathrm{C}$ & 1 & 60 & 2 days \\
Pre-Test & $\mathrm{R}, \mathrm{C} \& \mathrm{R}$ & 1 & 30 & 1 day \\
Practice & $\mathrm{R}, \mathrm{C} \& \mathrm{R}$ & 3 & 10 & $\begin{array}{c}\text { days during } \\
\text { a week } \\
\text { Post-Test }\end{array}$ \\
$\begin{array}{l}\text { Transfer of } \\
\text { skills }\end{array}$ & $\mathrm{R}, \mathrm{C} \& \mathrm{R}$ & 1 & 10 & 1 day \\
\hline
\end{tabular}

\section{Results}

The results obtained in this study were split into two sub-sections corresponding to each period, as follows.
Table 4.

Test Configuration in the Transfer of Skills Phase

\begin{tabular}{cccccc}
\hline Session & Robot & Classroom & Playground & $\begin{array}{c}\text { Known } \\
\text { Game } \\
\text { Partners }\end{array}$ & $\begin{array}{c}\text { Unknown } \\
\text { Game } \\
\text { Partners }\end{array}$ \\
\hline 1 & $\mathrm{X}$ & $\mathrm{X}$ & $\mathrm{X}$ & $\mathrm{X}$ & \\
2 & $\mathrm{X}$ & & $\mathrm{X}$ & \\
3 & & $\mathrm{X}$ & & & $\mathrm{X}$ \\
\hline
\end{tabular}

\section{Period 1}

The results of this period are for the matter qualitative. Figure 2 shows the interaction time (in percentage) of the two children along the sessions. As it can be verified, Case 3 interacted with the robot more than $80 \%$ of the time session. Concerning Case 4 , it was verified an increase in the interaction time from $65 \%$ up to $77 \%$.

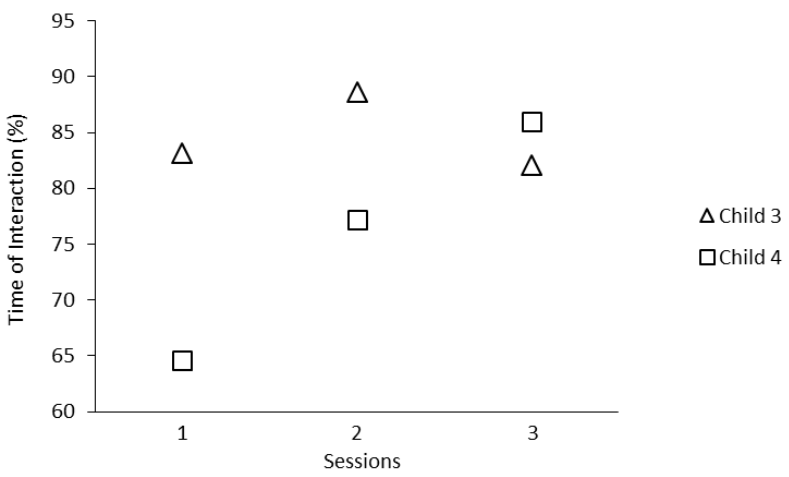

Figure 2. Interaction time (in percentage) along the sessions for child 3 and 4 in Period 1

Case 3 Task 1: Activation of the robot through sound. Firstly, the movement of the robot was enabled through music played by the computer, which seemed not to please the child, as he covered his face with his hands every time the music was played.

The robot activation signal, music, was then substituted by clapping hands on the floor. Repeatedly, the child tried to activate the movement of the robot, banging his hand on the floor and throughout the session, Case 3 showed interest in the movement of the robot. When the investigator asked for the robot, he gave it back. The positive reinforcement seemed to encourage Case 3, but he had difficulty in sitting upright for the session, always changing position, as lying on the side, front or knees. The rotating arm attracted the attention of Case 3 and he was able to activate the robot by hitting his hand on the floor or clapping.

In the 2 nd session, Case 3 remembered easily what he should do to activate robot motion, clapping his hands on the floor. When the music started playing, he maintained the uncomfortable behaviour, although less intense, shown 
in the previous session. Case 3 presented some repetitive motor movements and he easily activated the robot motion for several times with intention.

In the 3rd session, Case 3 easily remembered what he should do to activate the robot's motion, clapping his hands or hitting his hands on the floor. On his own, and for several times, he hit his hands on the floor to activate the robot's movement. However, he hid his face when the music played. When he realized that the music triggered the movement of the robot, he carefully observed. Case 3 repeated several times "Look at the robot," calling the researcher for what it was doing, and he always accompanied its movement. Case 3 tried to push the robot to walk faster and he was involved with the robot, triggering its movement by producing sounds.

Summarizing, it can be seen in Figure 3 that the number of repetitive motor movements decreased compared to the first session; also the indicator "Ignores" decreased along the sessions, which means his interest on the robot increased along the sessions. Regarding the Action indicator, Case 3 manipulated the robot several times, having more manipulations in the last session, as well as verbalizations.

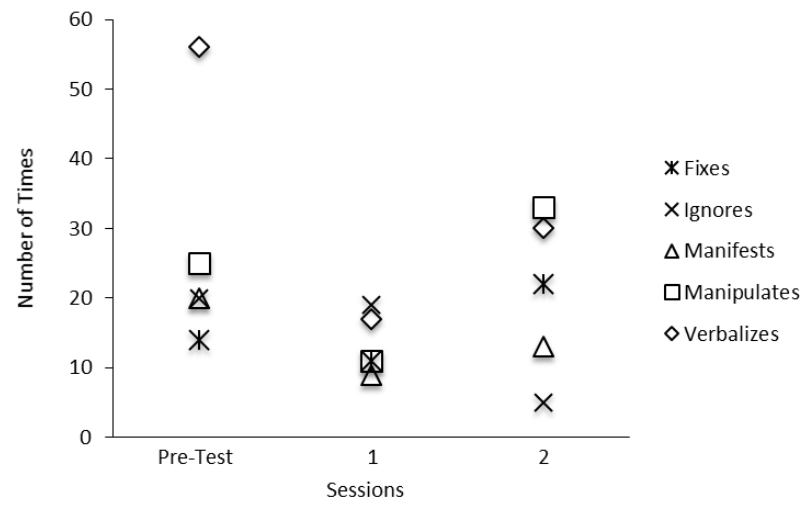

Figure 3. Frequency of the indicators in task 1 (Activation of the robot through sound) with case 3

Case 3 Task 2: Ball Game. In this task, Case 3 was very distracted and could not control his strength. Sometimes he hit himself in the head and threw the ball to a location other than the desired position. This experience was not as successful as expected.

In session 2, Case 3 had trouble throwing the ball through the rail, because he preferred the sound produced by his hands on the metal. Repeatedly, Case 3 tried to activate the robot hitting his hands on the floor. Case 3 did not realize what he had to do, although the researcher indicated him that he had to throw the ball. After no success in the experiment performed on the floor, it was decided to change the approach. The experiment was then performed on the table with the child, and the robot placed face to face while the rail was between them. Initially, Case 3 could not throw the ball along the rail, but through positive reinforcement he managed to do the task a few times. In total, only 15 times, Case 3 was able to send the ball with enough velocity so that the robot could return it back, with highest frequency at the end of the session.

As shown in Figure 4, Case 3 had some difficulties, but in the last session he sent the ball back more times than in the other sessions. In the second session he showed repetitive motor movements because he was more nervous than normal. The indicator "Ignores" decreased over the sessions, indicating that he preferred to interact, throwing the ball instead of only observing the robot.

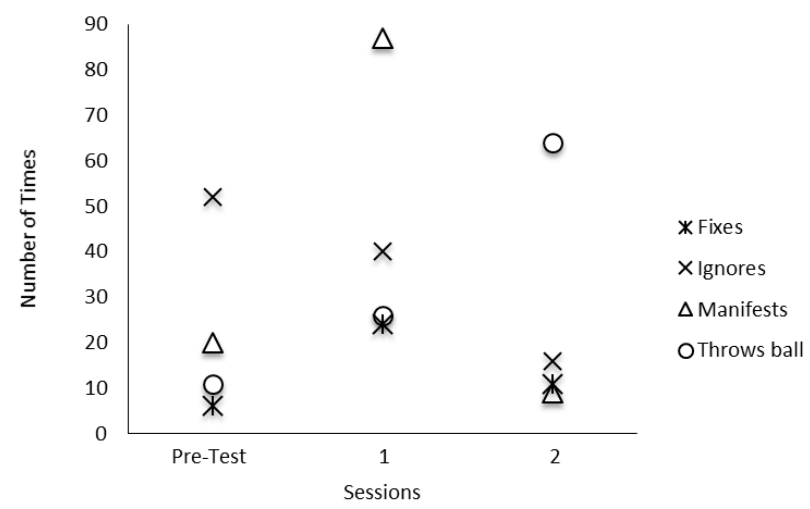

Figure 4. Frequency of the indicators in task 2 (Ball Game) with case 3

Case 3 Task 3: Call the Robot. Case 3 liked the fact that the robot reacted to the sound produced by him. He took the robot, vocalized several times, and interacted repeatedly hitting his hand on the floor to produce sound activating the sound sensor that moved the robot. He lay on the floor to observe the robot while he hit his hand. Case 3 manipulated the robot several times, but he held several repetitive motor movements, including banging his hand on the floor.

In session 2, for several times, Case 3 manipulated the robot, grabbing it. Case 3 established a turning-taking game with the researcher, where they took turns making sound by hitting with their hands on the floor activating robot movements.

In turn-taking game, Case 3 took turns at clapping hands with the researcher to get the robot in his direction. Even without the researcher at his side, he produced his own sound, to move the robot.

During this task, Case 3 almost did not perform any repetitive motor movements but at the same time, he had no intention to manipulate the robot (Figure 5).

Case 4 Task 1: Activation of the robot through sound. The robot's movement attracted the attention of Case 4 and he seemed to immediately realize that music was used to activate the movement. Often, Case 4 tried to stop the movement of the robot, and whenever he was far from the robot, he always tried to approach it. The robot's rotating arm attracted Case 4's attention. If the arm was trapped, for example, in his leg, he turned it away to allow 
the movement to continue. Case 4 ended up losing interest in the experiment after $6 \mathrm{~min}$.

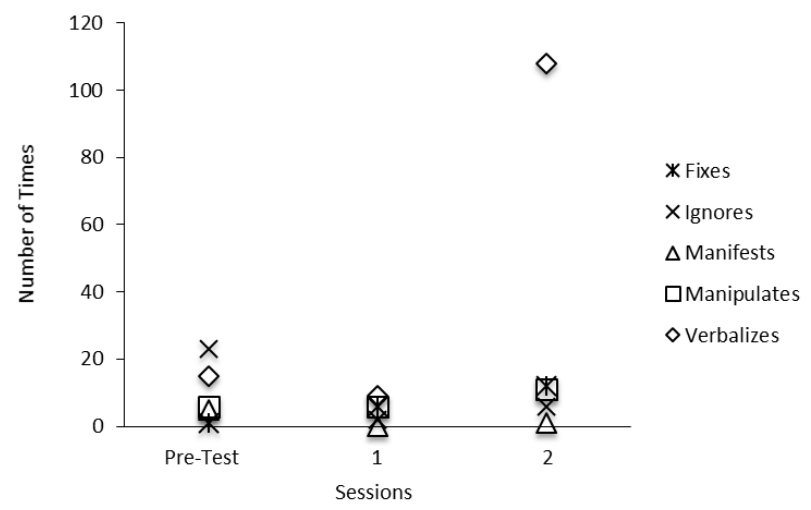

Figure 5. Frequency of the indicators in task 3 (Call the Robot) with case 3

In session 2, when the robot was far from him, Case 4 observed for a few seconds the robot movement, when activated by music. However, shortly he approached the robot to grasp it. For some time, Case 4 handled the robot with so much strength that he removed the rotating arm. The sound made by the rotating arm hitting the ground, caught the attention of Case 4.

In the third session, Case 4 was too attached to the robot, not releasing it so it could perform the movement when the music played. Again, Case 4 gave special attention to the rotating arm, even when he was far from the robot. When the music started playing, he approached the robot immediately to grab him. Throughout all the experiments, Case 4 was involved with the robot, either manipulating it or observing its motion, but he continued to show some repetitive motor movements (Figure 6).

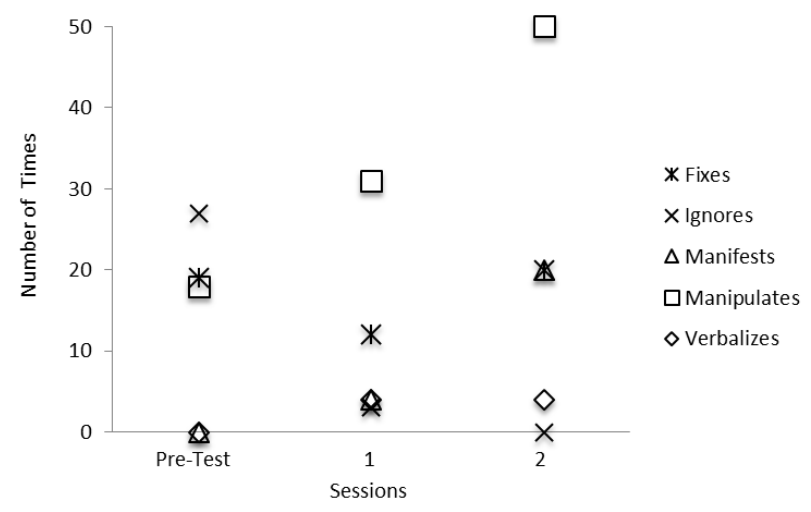

Figure 6. Frequency of the indicators in task 1 (Activation of the robot through sound) with case 4

Case 4 Task 2: Ball Game. The first time Case 4 touched the ball, he grabbed it and threw it to the corner of the room. In the ball game, Case 4 seemed more interested in approaching the robot, than to push the ball. For several times he hit the ball into the rail without sending it. Only four times, Case 4 was able to push the ball through the rail towards the robot.

In session 2, the experiment was held at the desk. After the first request, Case 4 took the ball and threw it out of the rail, repeating it at least four more times. With the researcher's encouragement and after a demonstration, Case 4 was able to get the ball three times. By the end of the session, Case 4 managed to get the ball towards the robot a few times, but less than those sent out of the rail.

In session 3, the first action of Case 4 was to take the ball and threw it out of the rail. This action was repeated several times. Only a few times, he was able to correctly place the ball on the rail and send it to the robot. By the end of the session, Case 4 managed to get the ball to the robot a few times, but still less than those sent out of the rail.

In Figure 7 we can observe the facts stated early. Case 4 did not understand Task 2 and did not cope with the researcher pushing the ball through the rail only a few times. It is possible to see that he performed a high number of repetitive motor movements, and he kept throwing the ball to the corner of the room.

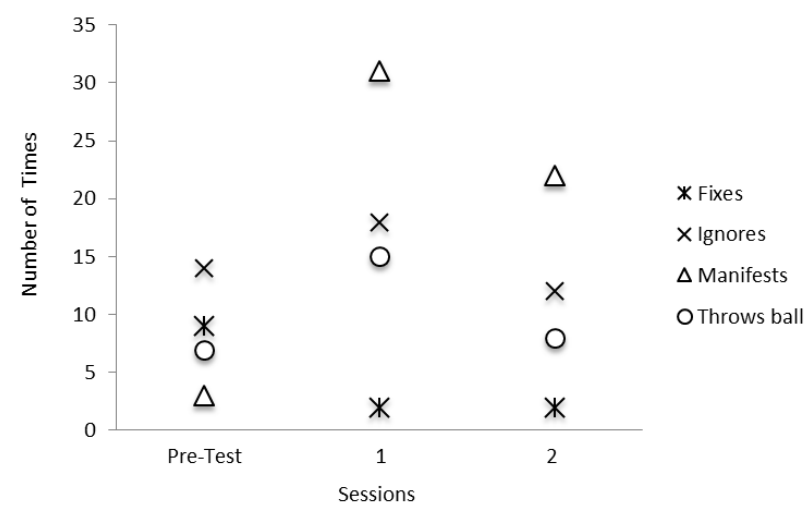

Figure 7. Frequency of the indicators in task 2 (Ball Game) with case 4

Case 4 Task 3: Call the robot. In the beginning, Case 4 only wanted to approach the robot so he could touch it. Case 4 was able to produce vocalizations to allow the movement of the robot and he showed some resistance when the robot was removed from his hands. He showed no initiative to call the robot without the encouragement of the researcher.

In session 2, after the researcher said "Come" towards the robot, Case 4 immediately repeated a similar sound, activating the movement of the robot. Case 4 was able to imitate the gesture and the sound of "come" for several times (Figure 8), moving the robot towards him. As the robot approached him, the first thing he did was to grab the rotating arm.

In session 3, Case 4 "automatically" made the sound learnt on the previous experiment and made the corresponding gesture with his hands. The interventions of Case 4 were sometimes alternated with the usual repetitive 
motor movements. The purpose of Case 4 was always to try to approach the robot, instead of letting the robot reach him. In the following attempts, if the researcher did not give any indication, Case 4 performed the sound and the associated gesture to call the robot.

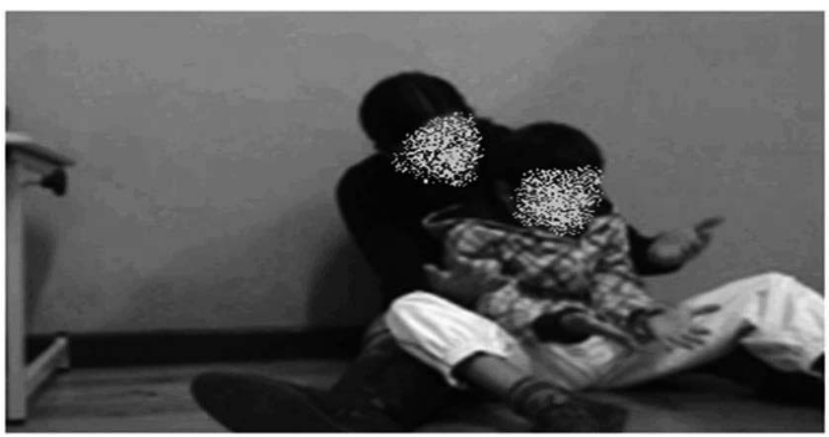

Figure 8. Case 4 in the second session (Task 3, Call the robot)

Case 4 has a more severe disorder and for him it was more difficult to understand the task rules. He continuously tried just to manipulate the robot, spinning its arm and grabbing it hard. The number of times he ignored the robot decreased largely during Task 1 , because he manipulated the robot most of time.

In the last task (Figure 9), Case 4 showed some interesting behaviours, executing the sound to call the robot and making the associated gesture in the last session. Despite his lack of communication, Case 4 seemed to understand that his voice command enabled the movement of the robot in his direction, and because he wanted to grab the robot he verbalized several times.

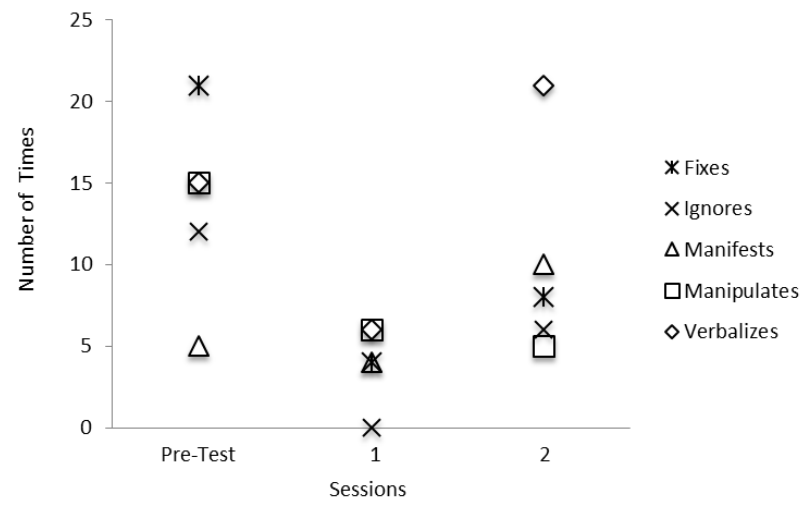

Figure 9. Frequency of the indicators in task 3 (Call the robot) with case 4

\section{Period 2}

The results obtained in the Pre-Test were considered as benchmark values to be compared to the results obtained in the other sessions. Thus, in 30 minutes of Pre-Test session, the child interacted with the robot $8 \mathrm{~m} 30 \mathrm{~s}$. In Pre-Test session, the child fixed the robot only four times (Fixes), ignoring it more than a hundred times (Ignores). He also showed repetitive motor movements almost 100 times (Manifests), manipulated the robot 58 times (Manipulates), 23 of which with the request of the researcher (Demands). In order to have a common basis for comparison between experiments and the reference level (Pre-Test), the 30 minutes of session results were re-scaled to the time duration of the other test sessions, 10 minutes. The indicator reference values, was then re-scaled to: Fixes -1 , Ignores - 37, Manifests - 31, Manipulates - 19, Demands -7 .

Table 5 presents the results obtained in the Practice phase (Figure 10). In the first session the child was engaged in the task $75 \%$ of the time, in the second session the engagement was around $50 \%$ and finally in the third session the engagement was higher than 64\%. In all sessions, the interaction was still above the obtained in the Pre-Test (around 28\%).

In these three sessions, we highlight the number of times in which the child fixed the experiment/robot and the reduced number of repetitive motor movements.

Table 5.

Practice Results (3 sessions) in Period 2 in terms of the predefined indicators

\begin{tabular}{llccc}
\hline Indicator & & \multicolumn{3}{c}{ Number of Times } \\
\hline Reaction & Fixes & 140 & 50 & 69 \\
& Ignores & 71 & 44 & 54 \\
& Manifests & 16 & 36 & 4 \\
\multirow{3}{*}{ Action } & Manipulates & 192 & 75 & 95 \\
& Demands & 37 & 37 & 40 \\
& Interaction in 10 minutes & $7 \mathrm{~m} 35 \mathrm{~s}$ & $5 \mathrm{~m} 44 \mathrm{~s}$ & $6 \mathrm{~m} 25 \mathrm{~s}$ \\
\hline
\end{tabular}

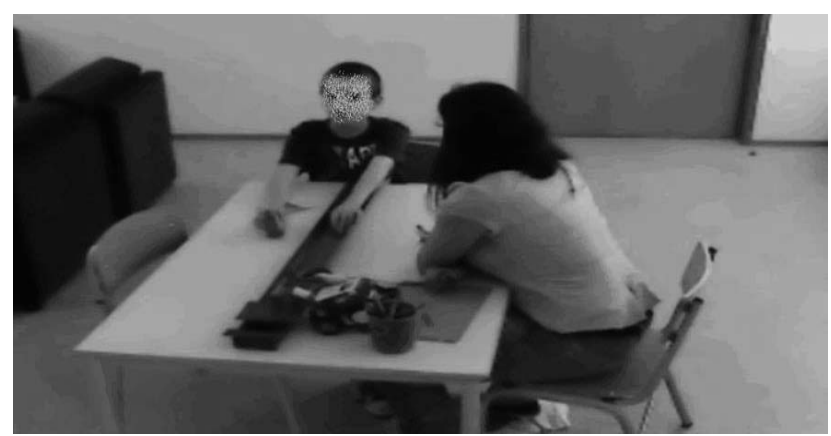

Figure 10. Practice phase of case 5

In the Post-Test session, after one week of interruption, the child was able to successfully answer to the initiative of the adult to interact. He did it 68 times, performing only 15 repetitive motor movements. The number of times he ignored the robot equalled the lowest value so far obtained, as well as in what concerns to the repetitive motor behaviour.

Finally, in the Transfer of Skills phase, different scenarios were tested: sessions in the playground and in the classroom with unknown partners. In the playground the 
child manipulated the robot without the need of the researcher's request. The number of repetitive motor movements registered compared to the Pre-Test was not significant and the time of interaction was higher than $90 \%$. The number of times the child ignored the activity in the playground was slightly the same of the Pre-Test but it was due to surrounding distractions (bus movement, for example). The last scenario included an unknown game partner to play with in the classroom. It is important to underline that this session was performed without the robot, exactly to see if the child could transfer the game's objective with a human partner, without the mediator. The interaction time reached almost $100 \%$.

Table 6 summarizes the results in Period 2. According to the feedback given by the psychologist that accompanies this child, few months later, after holidays and when returning back to school, the child managed to ask for a glass of water, performing the same trained gestural interaction when having lunch in the cafeteria and that action was repeated more times.

Table 6.

Results' Comparison in Period 2 in the different phases considered in terms of the re-defined indicators

\begin{tabular}{|c|c|c|c|c|c|c|}
\hline \multicolumn{2}{|c|}{ Indicator } & \multirow[b]{2}{*}{ Pre-Test } & \multirow[b]{2}{*}{$\begin{array}{l}\text { Practice } \\
\text { (Average) }\end{array}$} & \multicolumn{3}{|c|}{ Number of Times } \\
\hline & & & & Post-Test & $\begin{array}{l}\text { Playground: Known } \\
\text { Game Partner }\end{array}$ & $\begin{array}{c}\text { Playground: Unknown } \\
\text { Game Partner }\end{array}$ \\
\hline \multirow[t]{3}{*}{ Reaction } & Fixes & 4 & 86 & 73 & 80 & 61 \\
\hline & Ignores & 112 & 56 & 45 & 49 & 39 \\
\hline & Manifests & 93 & 19 & 15 & 10 & 8 \\
\hline \multirow[t]{2}{*}{ Action } & Manipulates & 58 & 121 & 68 & 72 & 50 \\
\hline & Orders & 23 & 38 & 29 & 1 & 39 \\
\hline \multicolumn{2}{|c|}{ Interaction in $10 \mathrm{~m}$} & $2 \mathrm{~m} 50 \mathrm{~s}$ & $6 \mathrm{~m} 35 \mathrm{~s}$ & $9 \mathrm{~m} 12 \mathrm{~s}$ & $9 \mathrm{~m} 15 \mathrm{~s}$ & $9 \mathrm{~m} 23 \mathrm{~s}$ \\
\hline
\end{tabular}

\section{Discussion}

Advances in recent years have enabled robots to fulfil a variety of human-like functions, as well as to aid with the goal of improving several skills (Feil-Seifer \& Matarić, 2009; François et al., 2009; Robins et al., 2004;Wainer, Ferrari, Dautenhahn, Robins, 2010).

In Period 1, the research question was: 'Can the robot be used to reduce repetitive motor movements and improve joint attention in children with ASD?' After this experimental study, there are no conclusive answers regarding reducing motor repetitive motor movements while using robotic platforms in the intervention sessions. Nevertheless, the qualitative analysis of the videos revealed that the children's joint attention increased over the sessions. These results are contradictory with other studies, which refer that, the use of robots could elicit repetitive motor behaviours (Lund et al., 2009; Stribling et al., 2009).

In future work, the research team wants to address the measure of repetitive motor movements performed during the sessions as an indicator of anxiety of the children, analyzing how this behaviour evolves along time.

In Period 2, the research team wanted to answer the research question: 'Can the robot be assumed as promoting stimulus in establishing social interactions with children with ASD, in new context and environments?'. The results obtained in all phases (Table 6) compared to the ones from the Pre-Test session, and considering that the child manifested difficulties in directing and keeping the attention, points towards a positive response to the initial research question. In fact, the child managed to perform the task in several constraints, despite the weak results in the Pre-Test. Although, when defining the experiences, the therapists doubt the child could successfully accomplish the test. In the end, and in spite of being in different environments and with unknown partners, the child managed to interact and play with others as well as pronouncing simple words. It is worth referring that it was the first time the child played, for a long time interval, with the robot and with known and unknown partners.

The research reinforces the importance of robots in developing social skills and stresses its role in the promotion of triadic interactions with another child, another parent, or another professional (Duquette, Michaud, \& Mercier, 2008; Feil-Seifer, \& Matarić, 2009; Iacono, Lehmann, Marti, Robins, \& Dautenhahn, 2011; Wainer, Ferrari, Dautenhahn, \& Robins, 2010). Robots seem to work as a mediator tool able to call for attention of ASD, and therefore promote their social communication (Salter, Werry, \& Michaud, 2008).

\section{Conclusions}

In this paper the authors were particularly interested in answering the question "Can a LEGO robot (simple, lowcost, configurable and modular robot) contribute to promote social interaction and verbal and non-verbal communication in children with ASD?'

In this qualitative case-study, and in all experimental stages, it was verified that joint attention of the children increased over the sessions. These results confirm the initial aim of evaluating the potential of the LEGO platform by single subject design to mimic results achieved with dedicated robot designs concerning the use of robot systems to help encourage social interactions for children with ASD. This reinforces conclusions that robots seem, in fact, powerful tools that should be explored concerning this target population. Furthermore, we addressed the question 
of whether there was a transfer of the new acquired skills. Results show that for the studied case studies there was an effective transfer of skills.

Nevertheless, we are aware that during the educational process, children with ASD can be influenced by many factors and variables. We know that changes in the performance of the children, more specifically its effects on everyday social and emotional skills, may not be due solely to the intervention process carried out. Secondly, we cannot ignore the subjectivity levels in the evaluation of the social skills of the teachers and family. Finally, as the study includes three children, the results can be only truly descriptive. Hence, this study cannot generalize the results to the entire population of individuals with ASD. In some cases, low-cost Lego robots can be an interesting tool to be used as a mediator in the intervention sessions with children with ASD.

In future work, special attention will be devoted to understand the evolution of interaction with time and in different conditions/scenarios, always using triadic relationships. It is also our aim to extend this research to more children with ASD, focusing in early intervention with children with age between 6 and 10 years old.

\section{Referencias}

American Psychiatric Association (APA). (2013). Diagnostic and statistical manual of mental disorders (5th ed., Text Revision). Arlington, VA: APA.

Billard, A., Robins, B., Dautenhahn, K., \& Nadel, J. (2007). Building Robota, a Mini-Humanoid Robot for the Rehabilitation of Children with Autism. The RESNA Assistive Technology Journal, 19, 37-49. http://dx.doi. org/10.1080/10400435.2007.10131864

Bregman, J. D., Zager, D., \& Gerdtz, J. (2005). Behavioural interventions. In Volkmar FR, Paul R, Klin A, Cohen D. (eds). Handbook of Autism and Pervasive Developmental Disorders (897 -924). Hoboken NJ: John Wiley \& Sons.

Brooks, R., Breazeal, C., Marjanovic, M., Scassellati B., \& Williamson, M. (1998). The Cog Project: Building a Humanoid Robot. In C. Nehaniv (Ed.), Computation for Metaphors, Analogy and Agents (pp.52-87). Berlin: Springer-Verlag.

Campbell, J. M. (2003). Efficacy of behavioural interventions for reducing problem behaviour in persons with autism: A quantitative synthesis of single-subject research. Research in Developmental Disabilities, 24, 120 -138. http://dx.doi.org/10.1016/S0891-4222(03) 00014-3

Conroy, M. A., Boyd, B. A., Asmus, J. M. \& Madera, D. (2007). A functional approach for ameliorating social skills deficits in young children with autism spectrum disorders. Infants \& Young Children, 20, 242-254. http://dx.doi.org/10.1097/01.IYC.0000277755.93313.7d

Dautenhahn, K. (1999). Robots as Social Actors: AURORA and the Case of Autism. In Proceedings
CT99, The Third International Cognitive Technology Conference (pp.359-374). East Lansing, MI: Michigan State University

Davis, M., Otero, N., Dautenhahn, K., Nehaniv, C.L., \& Powell, S.D., (2007). Creating a software to promote understanding about narrative in children with autism: Reflecting on the design of feedback and opportunities to reason, development and learning. ICDL 2007. In IEEE, Proceedings in IEEE 6th International Conference (pp.64-69), Atlanta, http://dx.doi.org/10. 1109/DEVLRN.2007.4354045

Duquette, A., Michaud, F., \& Mercier, H. (2008). Exploring the use of a mobile robot as an imitation agent with children with low-functioning autism. Auton Robot, 24, 147-157, http://dx.doi.org/10.1007/s10514007-9056-5

Feil-Seifer, D., \& Matarić, M. (2009). Toward socially assistive robotics for augmenting interventions for children with autism spectrum disorders. Experimental Robotics, 54, 201-210.

François, D., Powell, S., \& Dautenhahn, K. (2009). A longterm study of children with autism playing with a robotic pet: Taking inspirations from non-directive play therapy to encourage children's proactivity and initiative-taking. Interaction Studies, 10, 324-373.

Giullian, N.; Ricks, D.; Atherton, A.; Colton, M.; Goodrich, M.; \& Brinton, B. (2010). Detailed requirements for robots in autism therapy, Systems Man and Cybernetics (SMC) In Procs IEEE International Ultrasonics Symposium (pp.2595-2602). San Diego: IEEE, http://dx.doi.org/10.1109/ICSMC.2010.5641908

Horner R. H., Carr E. G., Strain P. S., Todd A. W., \& Reed H. K. (2002). Problem behaviour interventions for young children with autism: A research synthesis. $J$ Autism Dev Disord, 32, 423 -446.

Iacono, I., Lehmann, H., Marti, P., Robins, B., \& Dautenhahn, K. (2011). Robots as social mediators for children with autism: A preliminary analysis comparing two different robotic platforms. In procs IEEE International Conference on Development and Learning, (pp. 1-6). Frankfurt: IEEE

Kozima, H., Nakagawa, C., \& Yasuda, Y. (2007). Children-robot interaction: a pilot study in autism therapy. Progress in Brain Research, 164, 385-400. http://dx.doi.org/10.1016/S0079-6123(07)64021-7

Kozima, M., Michalowski, P., \& Nakagawa, C. (2008). Keepon: A Playful Robot for Research, Therapy, and Entertainment. International Journal of Social Robotics, 1, 3-18. http://dx.doi.org/10.1007/s12369008-0009-8

Lund, H., Pederson, M. D., \& Beck, R. (2009). Modular robotic tiles: Experiments for children with autism. Artificial Life and Robotics, 13, 393-400.

Marans W. D., Rubin E., \& Laurent A. (2005). Addressing social communication skills in individuals with highfunctioning autism and Asperger syndrome: critical 
priorities in educational programming. In Volkmar F. R, Paul R, Klin A, \& Cohen D, (Eds). Handbook of Autism and Pervasive Developmental Disorders (977 -1002). Hoboken: John Wiley \& Sons.

Olley J. G. (2005), Curriculum and classroom structure. In Volkmar F. R, Paul R, Klin A, \& Cohen D, (Eds). Handbook of Autism and Pervasive Developmental Disorders (863 -881). Hoboken: John Wiley \& Sons.

Paul R., \& Sutherland D. (2005). Enhancing early language in children with autism spectrum disorders. In Volkmar F. R, Paul R, Klin A, Cohen D, (Eds.) Handbook of Autism and Pervasive Developmental Disorders (946976). Hoboken: John Wiley \& Sons.

Robins, B., Dickerson, P., Stribling, P., \& Dautenhahn, K. (2004). Robot-mediated joint attention in children with autism: A case study in robot-human interaction. Interaction Studies, 5(2), 161-198.

Robins, B., Otero, N., Ferrari, E. \& Dautenhahn, K. (2007). Eliciting Requirements for a Robotic Toy for Children with Autism - Results from User Panels. In Procs 16th IEEE Int Symp on Robot and Human Interactive Communication (ROMAN2007) (pp. 101-106). Jeju, Korea: IEEE, http://dx.doi.org/10.1109/ROMAN.2007. 4415061

Robins, B., Dautenhahn, K., \& Dickerson, P. (2009). From Isolation to Communication: A Case Study Evaluation of Robot Assisted Play for Children with Autism with a Minimally Expressive Humanoid Robot. 2009 Second International Conferences on Advances in ComputerHuman Interactions, Cancun, México, http://dx.doi.org/ 10.1109/ACHI.2009.32
Rutherford, M. D., \& McIntosh, D. N. (2007). Rules versus prototype matching: Strategies of perception of emotional facial expressions in the autism spectrum. Journal of autism and Developmental Disorders, 37, 187-196, http://dx.doi.org/10.1007/s10803-006-0151-9

Salter, T., Werry, I., \& Michaud, F. (2008). Going into the wild in child-robot interaction studies: issues in social robotic development. Intel Serv Robotics, 1, 93-108.

Schopler, E., Reichler, R., DeVellis, R., \& Daly, K. (1980). Toward objective classification of childhood autism: Childhood Autism Rating Scale (CARS). Journal of Autism and Developmental Disorders, 10, 91-103, http://dx.doi.org/10.1007/BF02408436

Stribling, P., Rae, J., \& Dickerson, P. (2009). Using conversation analysis to explore the recurrence of a topic in the talk of a boy with autism spectrum disorder. Clinical Linguistics and Phonetics, 23, 555-582.

Taylor B. A. (2001). Teaching peer social skills to children with autism. In Maurice C, Green G, Foxx RM (Eds.), Making a Difference: Behavioural Intervention for Autism (83-96). Austin, TX: Pro-Ed.

Wainer, J., Ferrari, E., Dautenhahn, K., \& Robins, B. (2010). The effectiveness of using a robotics class to foster collaboration among groups of children with autism in an exploratory study. Personal Ubiquitous Computing, 14, 445-455.

Warren, Z. E., Bekele E., Weitlauf, A. F, Zheng, Z., Zhang, L., Sarkar, N., Swanson, \& et al. (2013). Can Robotic Interaction Improve Joint Attention Skills? J. Autism Dev Disorders, 45, 3726-34, http://dx.doi.org/10.1007/ s10803-013-1918-4

Fecha de recepción: 22 de febrero de 2016. Fecha de aceptación: 29 de junio de 2016. 